\title{
Investigação Participativa como Processo de Melhoria da Práxis Docente
}

Ginete Cavalcante Nunes ${ }^{1}$; Maria Aparecida Carvalho Alencar Luz ${ }^{2}$

Resumo: A investigação participativa parte do pressuposto de que o professor é competente e capacitado para formular questões relevantes no âmbito da sua prática ,para identificar objetivos a prosseguir, para escolher as estratégias e metodologias apropriados para atuar em conformidade, para monitorar tanto os processos como os resultados. No que se refere à educação, a investigação participativa permite a articulação entre os saberes científicos e os saberes práticos, fazendo emergir novos conhecimentos sobre a realidade educativa. Um dos pressupostos fundamentais de qualquer forma de investigação participativa é a convicção de que essa investigação é a ação podem e devem caminhar juntos.

Palavras-chave: Investigação participativa. Estratégias metodológicas. Saberes científicos.

\section{The Research Participatory as Process for Improving Academic Praxis}

\begin{abstract}
The participative research comes of the teacher assumption is competent and able to formulate relevant questions in its practice, to identify goals to pursue, to choose the strategies and appropriate methodologies to act accordingly to both monitor the processes and the results . With regard to education, participatory research allows the articulation between scientific knowledge and practical knowledge, giving rise to new knowledge about the educational reality. One of the fundamental assumptions of any form of participatory research is the conviction that research is the action can and must go together.
\end{abstract}

Keywords: Participatory Research. Methodological approaches. scientific knowledge.

\section{Introdução}

A palavra "Investigação" vem do verbo latino "vestígio" que significa "seguir as pisadas".Significa,portanto,a busca de algo a partir de vestígios;esse tipo de investigação é muito diferente das pesquisa tradicional. No que se refere à educação, a investigação participativa permite a articulação entre os saberes científicos e os saberes práticos, fazendo emergir novos conhecimentos sobre a realidade educativa.

\footnotetext{
${ }^{1}$ Graduada em Letras, língua Inglesa, pela Faculdade de Formação de Professores de Araripina - FAFOPA Especialização em Políticas Educativas e Docência do Ensino Superior pela Faculdade de Formação de Professores de Araripina - FAFOPA. Cursando Mestrado Profissional em Letras - PROFLETRAS, pela Universidade Federal Rural de Pernambuco - UFRPE. Docente na Faculdade de Formação de Professores de Araripina - FAFOPA. Autor correspondente. E-mail: ginetecavalcante@bol.com.br;

${ }^{2}$ Graduação em Pedagogia, Supervisão Escolar, pela Faculdade de Ciências Humanas do Sertão Central. Especialista em Gestão Educacional. Docente na Faculdade de Formação de Professores de Araripina - FAFOPA. Analista em Gestão Educacional pela Secretaria Educação de Pernambuco.
} 
Um dos pressupostos fundamentais de qualquer forma de investigação participativa é a convicção de que essa investigação é a ação podem e devem caminhar juntos. Caminhar juntas não significa apenas uma concomitância temporal,mas essencialmente uma articulação dialética desses dois aspectos o fazer e pesquisar fazendo.Na pesquisa critica ,é fundamental que o fazer junto signifique também a construção de movimentos intersubjetivos, inter dialogais, inter comunicantes. Esses movimentos irão construindo um universo de significações coletivas organizando pelas mediações entre as experiências e os saberes individuais,formando uma rede de co-formadora e gerando processos de auto formação continuada.

Na abordagem de José B. Duarte (2012 p.01) esse tipo de investigação é muito diferente da pesquisa tradicional...no sentido de que essa pesquisa é muito interessante,por exemplo ,em termos de desenvolvimento da profissionalidade docente (por que possibilita ,entre outras finalidades,a análise da própria prática profissional com registros adequados).

A investigação participativa parte do pressuposto de que o professor é competente e capacitado para formular questões relevantes no âmbito da sua prática ,para identificar objetivos a prosseguir, para escolher as estratégias e metodologias apropriados para atuar em conformidade, para monitorar tanto os processos como os resultados .

A investigação participativa tem uma dimensão importantíssima para a ação/reflexão do professor,pois ,a prática reflexiva leva consequentemente a uma melhoria da práxis .É muito relevante o que afirma Oliveira-Formossinho e Kihimoto,

Este é um avanço qualitativo no que se refere que a imagem de professor quer á teoria da formação de professores ,o professor passa de objetivo da investigação dos acadêmicos a sujeito da sua própria investigação.Enquanto ator,assume o questionamento ,da reflexão profissional contextual.Como a maioria das correntes de investigação ,ação desafia os profissionais a desenvolver este processo de forma cooperada ,podemos dizer que, assim, se realiza um duplo avanço qualitativo :de objeto a sujeito de investigação ,por um lado, de sujeito a participante de um processo cooperado de investigação ,por outro (OLIVEIRA-FORMOSINHO, KISHIMOTO 2002, p.26).

Na linguagem de Paulo Freire - que, dentro da corrente comunitária, é considerado um segundo fundador da investigação - ação -,esse processo de passagem de objeto a sujeito,de sujeito a participante num processo cooperando é um processo de conscientização que redefine o estatuto hierárquico entre o professor e o investigador ,quer o estatuto hierárquico entre investigação e a ação.

Desse ponto de vista o que se propõe é a utilização da pesquisa-ação ou pedagógica como meio de produzir conhecimento sobre o cotidiano de trabalho,com o intuito de atingir melhorias no desenvolvimento profissional dos sujeitos ,da coletividade investigada ,assim como das instituições educacionais envolvidas,desafiando o professor a partir de sua prática docente ,pela ação em grupos integrados ,cooperativos .Busca-se assim a profissionalização continuada ,a superação de situações ou problemas práticas num processo espiral reflexivo, investigativo e sobretudo participativo . 
Desta maneira verifiquemos o que diz Freire (1996):

A prática docente critica ,implicante do pensar certo,envolve o movimento dinâmico ,dialético ,entre o fazer e o pensar sobre o fazer.O saber que a prática docente espontânea ou quase espontânea , "desarmada" , indiscutivelmente produz é um saber ingênuo ,um saber de experiência feito,a que falta a rigorosidade metódica que caracteriza a curiosidade epistemológica do sujeito. (FREIRE ,1996,p.38)

Freire (1996) ainda ressalta que:

(...) Na formação permanente dos professores, o momento fundamental é o da reflexão critica sobre a prática. É pensando criticamente a prática de hoje ou de ontem que se pode melhorar a próxima prática. $\mathrm{O}$ próprio discurso teórico ,necessário á reflexão critica ,tem de ser de tal modo concreto que quase se confunda com a prática .O seu " distanciamento" epistemológico da prática enquanto objeto de sua análise ,deve dela " aproximá-lo" ao máximo quanto melhor faça esta operação tanto mais inteligência ganhar na prática em análise e maior comunicabilidade exercem torno da superação da ingenuidade pela rigorosidade .Por outro lado ,enquanto mais me assumo como estou sendo e percebo a ou as razões de ser de por que estou sendo assim,mais me torno capaz de mudar,de promover-me ,no caso,do estado de curiosidade ingênua para o de curiosidade epistemológica. (FREIRE ,1996,P.39)

Como a investigação participativa caracteriza-se por uma ação sistemática ,coordenando pelo pesquisador baseando em objetivos estabelecidos coletivamente e pesquisador como aquela que possua condição humana que the permite flexibilidade para lidar com dúvidas ,incertezas e ambigüidades ,aceitando um esquema de trabalho aberto,em que as decisões possam se tomadas na medida e no momento em que se fizeram necessárias .Sobretudo o professor investigador tenha habilidade comunicativa e estabeleça empatia com a equipe ,com os alunos ,formulando questionamentos, ouvindo atentamente e sendo extremamente paciente.

Popper (1992,p.80) considera que a prática reflexiva parece muito interessante por envolver os professores no questionamento da sua atividade diária mas , para que se baseie num registro adequado das situações e seja contextualizado em teorias como " tentativas de explicação e , logo de solução de um problema.

É essencial a capacidade de colocar-se no lugar do outro ,buscando entender melhor o que diz ,sente ,percebe,pois,tanto os investigadores não apenas clientes ou objetos ,mas como pessoas que pensam e sentem ,para que dessa forma se crie um clima de confiança ,para que os dados coletados ao longo do processo sejam significativos .Apresenta-se também como fundamental a competência para realizar corretamente a expressão escrita registrando o que se observou ,viu,ouviu e coletou na sua investigação.

Segundo José B. Duarte em seu artigo "Investigação participativa ,um gênero menor ?" :

A observação de aulas de outros professores permite um natural distanciamento dos fenômenos, necessários á análise .Mas a reflexão sobre as próprias aulas ,com base 
mediações ou registros adequados ,contém em maior grau a condição necessária á compreensão - a participação - que na observação das aulas dos outros é também necessária através da observação participante (DUARTE,2012, p.03.).

Quando um professor se torna observador de sua própria prática ele consequentemente se faz um profissional critico da sua práxis ,pois permite uma maior "naturalidade" e "flexibilidade" da observação ,neste caso nos convém citar mais uma vez Paulo Freire quando diz:

Não há ensino sem pesquisa e pesquisa sem ensino.Esses que fazeres se encontram um no corpo do outro .Enquanto ensino continuo buscando, reprocurando .Ensino por que busco,por que indaguei ,por que indago e me indago .Pesquisando para conhecer o que ainda não conheço e comunicar ou anunciar a novidade (FREIRE,1996,p.29).

O conhecimento profissional prático é de natureza evolutiva ,o que significa que está aberto a mudança.Mudar o conhecimento profissional prático não é uma mera questão do prático individual ou do teórico alinhado ,pois requer uma ampla formação cultural e social tanto quanto uma mudança nos contextos profissionais,nas relações pessoais ,nas relações de poder que os habitam .

Toda a referência feita, nos remete a complexidade da investigação participativa essa complexidade advém na natureza dos seu objetivos ,que se inscreve em patamares diferentes : agir e investigar a ação para transformá-la ;formar na ação transformando-a ;e investigar a transformação.Estamos perante uma estratégia que visa formar para transformar através da investigação da transformação.Assim ,a investigação participativa forma,transforma e informa através da produção de conhecimento sobre a realidade em transformação ;transforma ao sustentar a produção da mudança praxiológica através de uma participação vivida, significada e negociada no processo de mudança ; forma, pois produzir a mudança e construir conhecimento sobre ela é uma aprendizagem experencial e contextual, reflexiva e colaborativa.

No âmbito educativo, produzir a mudança através da Investigação Participativa pode construir-se num importante processo emancipatório ao propor uma resposta a problemas concretos , situados , locais longe do frenesi normativo e da retórica nominalista - formular as questões a estudar , elaborar os objetivos a prosseguir e as metodologias para abordá-los e monitorá-los, definir formatos para avaliar os resultados .

O professor como sujeito e participante na Investigação Participativa colaborativa participa também na avaliação dos resultados e do impacto da ação , sem deixar essa tarefa meramente a autoridades externas ao processo , tais como a inspeção ou investigadores externos, mas de assumir proativamente a avaliação interna do processo , dos resultados e do impacto como parte integrante da investigação participativa .

O professor nesse processo não é nem objeto nem sujeito , mas participante nos processos avaliativos. Em suma , o que está fundamentalmente em questão na Investigação Participativa é o que afirma José B . Duarte em seu artigo Investigação participativa : 
Noutros termos, o que está sempre em causa, e também numa pesquisa implicada ou participante, é que a pesquisa se oriente por um problema -pergunta cujo sentido leva à escolha de quadros teóricos com que se vai interpretar o problema e tentar encontrar um caminho para resolvê-lo. Constitui-se assim uma problemática que orientará todo o processo de pesquisa, incluindo os instrumentos com que se vão coligir e analisar os dados, numa procura de rigor que permita ao leitor poder, com a sua análise do processo e dos dados, ajuizar da validade da pesquisa (DUARTE, 2012, p.06.)

Podemos dizer, de modo geral, que existem duas maneiras para delimitar, definir e formular um problema de pesquisa, e ambas nos parecem válidas . Naturalmente, quando expressamos isto , estamos partindo de alguns pressupostos : um deles é o de considerar que o pesquisador está envolvido , direta e indiretamente, na realidade na qual um matiz dela , abrangente ou não , apresenta uma situação que precisa ser esclarecida.Isto significa que o investigador , ainda que não necessariamente , deve pertencer à área onde está surgindo, ou surgiu, a questão problemática .

Em outros termos,talvez seja recomendável que um educador procure esclarecer as interrogativas que emergem do âmbito educacional ou, pelo menos, participe como integrante de equipes de pesquisa que pretendam elucidar determinadas realidades que preocupam a escola.Pela singular característica das ciências sociais, e especificamente da educação, é possível que um sociólogo, um psicólogo ou um antropólogo, por exemplo, possam realizar pesquisar em torno de tópicos determinados da vida escolar, com maior segurança.Parece-nos,verdadeiramente, que, pela índole do trabalho realizado na escola e pela natureza da educação como caudal de saberes de muitos afluentes, quase não é possível realizar uma pesquisa científica prescindindo de equipes multidisciplinares.

Toda essa discussão remete à complexidade da Investigação Participativa .Essa complexidade advém também da integração dos papéis educacionais do professor com o papel de investigador , advém da aproximação do subjetivo e do objetivo , do prático e do investigador, do observador e do observado.

Este é também um contributo para um processo de emancipação, pois o professor, como prestador de um serviço social essencial, sabe que todos os serviços sociais devem ser analisados nas suas conseqüências. Concebemos o professor como um profissional que realiza um trabalho de natureza pública , que o compromete moralmente , pois o exercício de sua profissionalidade ocorre em um contexto de práticas institucionais e sociais e no que concerne às práticas institucionais $\backslash$ educacionais essa investigação como afirma DUARTE deve se orientar por um problema - pergunta e que essa problemática orientará todo o processo da pesquisa.

Nesse sentido, entende-se que o profissional da educação é antes de tudo um agente de transformação social e assim sendo abordaremos o potencial pedagógico da Investigação Participativa . Para tanto enfocamos os pressupostos que fundamentam a ação do professor como um intelectual crítico , capaz de produzir e recriar saberes, bem como as condições de formação de um 
professor autônomo que busca no conhecimento qualificado as possibilidades para renovar e inovar em sua prática educativa . A Investigação Participativa é vista em sua concepção formativoemancipatória , dando sustentação às concepções que referendam a necessidade e a possibilidade de formação do professor investigador .

Franco (2003 a, p.99) considera que todos os envolvidos na prática reflexiva precisam constituir-se em investigadores no contexto da práxis , e nesse sentido poderão desenvolver saberes no sentido de sua emancipação como sujeitos. Esses saberes referem-se tanto a predisposições para participar de um processo de pesquisa como à disponibilidade para se construir como pesquisador de sua prática ou, ainda, à possibilidade de se transformar em um sujeito produtor de conhecimento .

No que se refere à observação das atividades escolares, ou da aula pelo professor investigador vale apena analisar o que diz DUARTE :

(...) a gravação das aulas e sua eventual transcrição permitem ao professor uma reflexão sobre pormenores de que se não deu conta no decurso das aulas .Essa racionalização descobre formulações deficitárias que urge corrigir, , mostra que o encadeamento das sequências de aprendizagem poderia ter sido outro, o que terá evidentes conseqüências positivas na construção ou consolidação da identidade do professor como pessoa e como profissional (DUARTE , 2012 , p .07).

A prática reflexiva aponta a necessidade de que o professor desenvolva atitudes como estudos sistemáticos , motivação, estusiasmo , compromisso e responsabilidade com a sala de aula . Soma-se a isso a competência do docente para interrogar e refletir sobre e com os sujeitos envolvidos nos processos educativos empreendidos , pois somente assim poder-se-á obter mudanças baseadas tanto nos conhecimentos teóricos como nos produzidos a partir da análise e da investigação sobre a própria prática em aula , fazendo seus registros pessoais para a construção da identidade e profissionalidade .

Essa situação requer que os pesquisadores adentrem a dialética da realidade social , compreendam e acompanhem a dinâmica do movimento da práxis do sujeito construtor de sua realidade , estejam atentos ao saber produzido na prática social humana e, consequentemente, às transformações que tal dinâmica vai produzindo nos sujeitos e nas circunstâncias em transformação .Percebemos na prática a importância de o pesquisador estar atento para realizar as interpretações em contexto , para perceber as mediações do particular com a totalidade, para ressignificar a dinâmica das contradições inerentes ao movimento histórico , sempre respeitando e superando as sínteses provisórias de saber que vão se constituindo .

Concluimos então que a complexidade dos métodos é inevitável na Investigação Participativa Educativa , pois esta parte do cotidiano de um processo de ensino- aprendizagem que se caracteriza pela contradição, pela incerteza e pela indeterminação dos dilemas emergentes .

Essas características configuram uma realidade complexa em constante transformação que exige da criação do conhecimento um paradigma que lide com a complexidade .Um paradigma que 
Id on Line Revista Multidisciplinar e de Psicologia

Id on Line Multidisciplinary and Psychology Journal

use métodos plurais para compreender a realidade , sabendo-se que nenhum método a " faz falar " na sua totalidade .

Sem dúvida alguma os professores que vivenciam práticas de Investigação Participativa para a mudança revelam ganhos pessoais , tais como melhoria da autoestima e da autoconfiança , e ganhos profissionais, tais como maior capacidade de autoanálise, melhorias das interações com outros professores, desenvolvimento de atividades de colegialidade e desenvolvimento da atenção aos problemas dos alunos e à aprendizagem centrada nos alunos .

Desta maneira , temos aqui a trilogia de atributos que caracteriza o contributo da Investigação Participativa : ganhos na pessoa , na profissão e na prática educativa .

\section{Referências}

TRIVINOS ,Augusto Nibaldo Silva. Introdução a pesquisa em ciências sociais: a pesquisa qualitativa em educação, $1^{\circ}$ edição ,São Paulo,atlas .2011

DEMO, Pedro ; metodologia cientifica em ciências sociais; $3^{\circ}$ edição , São Paulo ,atlas 2009.

FRANCO , Maria Amélia Santoro ( 2003 a ) . Pedagogia como ciência da educação . Campinas , Papirus .

GAMBOA ,Silvio Sánchez ,pesquisa em educação: métodos e epistemologias, $2^{\circ}$ edição chapecó: Argos ,2012.

VERHAEGHE,Jean Cloude ;WOLFS,José Luiz ;SIMON,Xavier ;COMPERE ,Dominique . praticar a epistemologia -manual de iniciação para professores e formadores, $1^{\circ}$ edição ,edições loyola,São Paulo,2010.

POPPER ,Karl. Lógica das ciências sociais in :em busca de um mundo melhor .Lisboa: fragmentos, 1992 .P71-85.

DUARTE, J. B. Investigação participativa, um gênero menor? In: http://www.entrelugares.ufc.br/numero1/artigospdf/jose.pdf. Acesso em 14 de dezembro de 2015.

FREIRE ,Paulo pedagogia da Autonomia :saberes necessários à prática Educativa \Paulo Freire São Paulo: Paz e Terra ,1996 (Coleção Leitura ).

\section{Como citar este artigo (Formato ABNT):}

NUNES, G.C.; LUZ, M.A.C. A investigação participativa como processo de melhoria da Práxis docente. Id on Line Revista de Psicologia, Julho de 2016, vol.,10 n.30, Supl 1. p. 376-382. ISSN 1981-1179. 